\title{
COMPLIANCE E LEGISLAÇÃO ANTI-CORRUPÇÃO: UMA PERSPECTIVA COMPARADA.
}

\author{
Diogo De Almeida Viana Dos Santos ${ }^{1}$
}

\begin{abstract}
Resumo: A corrupção afeta crescimento econômico e livre-concorrência. A globalização dos mercados, transportes e telecomunicações estreitaram relações internacionais e de negócios. Este movimento trouxe para as empresas globais a necessidade de produzir com mais eficiência e agilidade, e criou ambiente mais favorável à corrupção. Convenções internacionais promovem práticas para combater a corrupção. A Convenção da OCDE tem se destacado. A criação e aplicação de leis anticorrupção e práticas de Compliance apresentam desafios. Este trabalho analisa a eficácia das leis anticorrupção em perspectiva comparada com foco nos Foreign Corrupt Practice Act(EUA 1977), UK Bribery Act(Reino Unido 2010) e na Lei brasileira anticorrupção(12.846/13).
\end{abstract}

Palavras-chave: Anticorrupção, Compliance, Direito comparado, Lei nº 12.846/13

\section{COMPLIANCE AND ANTI-CORRUPTION LAW: A COMPARATIVE PERSPECTIVE}

Abstract: Corruption affects economic growth and competition. The globalizations of markets, transportation and communications have narrowed international business relations. This process forces globalised comanies to produce more efficiently, but has also created opportunities for corruption. International Conventios promote practices to fight corruption Convenções internacionais promovem práticas para atingir este propósito. The OCED Convention has outreached to establish and enforce anticorruption rules and compliance practices. This paper analyzes the efficacy of compared anticorruption legislation, especially the Foreign Corrupt Practice Act(EUA 1977), UK Bribery Act(Reino Unido 2010) and the Brazilian anticorruption law(12.846/13).

Keywords: Anti-corruption law, Brazilian Law nº 12,846/13, Compliance, Comparative law

\footnotetext{
${ }^{1}$ Possui doutorado PhD em International Cooperation--Governance and Law - Universidade de Nagoya-Japão (2010), mestrado em LL.M. Comparative Law - Universidade de Nagoya-Japão (2007), graduação em Direito Bacharelado pela Universidade Federal do Maranhão (2003). Atualmente é professor de Direito Constitucional, Direito Internacional Público e Direito Econômico - Faculdade Pitágoras e UNESA. Foi Diretor do curso de Direito Bacharelado da Universidade Estadual do Maranhão. Tem experiência nas áreas de Direito Internacional Público e Ciência Política, com ênfase em Comportamento Legislativo, atuando principalmente nos seguintes temas: Direito Internacional, Teoria Constitucional, Federação, Propriedade Intelectual, e Responsabilidade Internacional.
} 


\section{INTRODUÇÃO}

Ao longo dos últimos vinte anos tem se percebido um forte incremento nas regras de controle institucional, no âmbito das grandes empresas, no setor público e, mais recentemente, entre as pequenas e médias empresas (independentemente do alcance geográfico de seus negócios) com o propósito de reduzir práticas de corrupção. A consciência de que práticas e condutas ilícitas nos negócios trazem prejuízo para o livre comercio e para o desempenho econômico e social dos países firmam a convicção sobre o problema da corrupção e a necessidade de controlá-la.

Uma das formas mais eficazes no fortalecimento do combate à corrupção têm sido a internacionalização da introdução de leis contra o suborno. Tais leis reduzem os incentivos à corrupção aumentando o custo e o risco incorridos pelas grandes empresas quando se detecta o pagamento de suborno a um funcionário do governo estrangeiro. Atualmente há leis deste tipo em quase todos os países com relações comerciais internacionais. Os Estados Unidos foram os pioneiros com a promulgação do Foreign Corrupt Practice Act de 1977. Em 2010, o Reino Unido promulgou o seu UK Bribery Act; em 2013, o Brasil promulgou a sua lei especifica sobre o tema: a "lei anticorrupção" (Lei nº. 12.846/13).

Todas elas trazem consigo um arcabouço jurídico no combate à prática do suborno que é baseado em temas como a responsabilização objetiva da pessoa jurídica, responsabilização do agente infrator nas ações comissivas e omissiva e o incentivo à adoção de programas de Compliance pelas empresas. Para Breier e Carril (2013), as questões de governança e Compliance nas empresas e no setor público já estão inter-relacionadas com questões no âmbito penal, permitindo que empresas, sejam elas públicas ou privadas, possam ser responsabilizas por atos delituosos.

No Brasil, os programas de Compliance circundam programas de prevenção no âmbito administrativos. Tal cenário abre margem para discussões complexas e longas sobre qual caminho o ordenamento jurídico brasileiro tende a seguir.

Dentro da atual realidade político-econômica brasileira, este trabalho se apresenta relevante para expandir a compreensão da sociedade e da comunidade acadêmica ao abordar o significado jurídico e as respectivas consequências da aplicação dos programas de Compliance como instrumentos de combate à corrupção; a sua relevância para o setor privado e sua 
institucionalização no ordenamento jurídico brasileiro, alcançando as entidades da administração pública.

Este trabalho se propõe a analisar os aspectos dos programas de Compliance como ferramenta de mitigação às práticas de suborno do agente público. Para responder a este objetivo, a pesquisa se propôs a responder Em que medida a institucionalização dos programas de Compliance contribuem efetivamente para o combate à corrupção; como as organizações privadas respondem a esta tendência?; quais os principais mecanismos e instrumentos jurídicos fomentam a criação os programas de Compliance?; apresentar os aspectos positivos já alcançados no Brasil e quais os seus principais desafios à sua plena adoção por empresas privadas e pelo setor público; quais os desafios a serem transpostos e as tendências futuras da legislação anticorrupção no Brasil?

Para o desenvolvimento deste trabalho, adota-se o pressuposto que: os programas de Compliance já são previstos em algumas leis de combate a corrupção no Brasil; a incorporação destes institutos na Lei $\mathrm{n}^{\circ}$. 12.846/13 é, em tese, um avanço no combate à corrupção, mas ainda é cedo para correlacionar sua vigência com o efetivo filtro contra as condutas ilícitas; as empresas veem se estruturando organizacionalmente para este novo cenário. Todavia, este movimento ainda é percebido somente nas grandes corporações; que as principais motivações para a adoção de sistema de Compliance no setor privado são a manutenção ou a busca pela competitividade nos seus mercados de operações, bem como a adoção das novas regras de relacionamento com o setor público e a preocupação com os danos à reputação a empresa frente aos seus clientes e a possibilidade da responsabilização objetiva por atos e corrupção e seus diretores e demais empregados.

A temática se desenvolve sobre uma abordagem histórica e conceitual quanto a prática do suborno por aos agentes públicos. Na sequência, é apresentada uma breve revisão bibliográfica sobre os efeitos mais visíveis da corrupção sobre as sociedades em geral. Avaliase os efeitos da corrupção no âmbito dos negócios privados e suas relações entre empresas e o setor público. Também se identifica os principais agentes de fomento contra as práticas de corrupção; quais mecanismos de ordem administrativa e jurídica são utilizados para o combate ostensivo à corrupção; qual o reflexo destes mecanismos na ordem jurídica e cada nação tomada como exemplo neste estudo. 
Na segunda parte, a abordagem foca na conceituação dos programas de Compliance, os seus elementos motivadores e sua gênese, os seus modelos ou roteiros de implantação; se há diferentes modelos aplicáveis às relações jurídicas entre o setor público e o setor privado; quais os impactos esperados no setor público.

Por fim, a terceira parte, faz uma análise comparativa entre as legislações antisuborno dos EUA, do Reino Unido e do Brasil. Primeiramente se apresenta as características conjunturais, jurídicas e processuais de cada legislação. Em seguida, é apresentada uma análise comparativa mostrando as convergência e divergências de cada legislação frente aos sistemas de Compliance aplicados no combate à corrupção de agentes públicos.

\section{CORRUPÇÃO DE AGENTES PÚBLICOS}

O setor público merece atenção por ser essencialmente o ente político que tem papel principal e primordial na construção das condições políticas, econômicas e jurídicas que fomentam o desenvolvimento de um país. As práticas de corrupção neste setor são, portanto, danosas às políticas públicas de distribuição de riquezas e de bem-estar social, bem como enfraquecem os princípios de democracia. Os efeitos e resultados da corrupção provém da participação de algum agente público, principalmente quando o ato praticado tem como terceiro interessado empresas privadas, independentemente de sua dimensão econômica.

Sendo a corrupção um problema que afeta as mais variadas jurisdições ao redor do mundo, observa-se a emergência de propostas e tentativas de solução para o pagamento de suborno aos agentes públicos e uso de recursos do Estado para obtenção de vantagens privadas. Ackerman (2016), OCDE (2017), Kennedy e Danielsen (2011) apontam que a adoção de mecanismos de boa governança empresarial são importantes elementos de contribuição para reduzir os riscos de desvios de recursos públicos diante de condutas e práticas ilícitas de empresas. Cabe aqui, breve explanação histórica para melhor compreensão da evolução destes mecanismos.

\subsection{PANORAMA HISTÓRICO}

Ao final da década de 1970, um novo paradigma começou a se delinear com o surgimento do “Foreign Corrupt Practices Act (FCPA)" aprovado em 1977 pelo Governo 
Americano. Esta lei foi considerada um marco paradigmático no controle de práticas incompatíveis com modelos de negócio no âmbito internacional (KENNEDY e DANIELSEN, 2011, p.5). Desde então, uma parcela economicamente significativa de países líderes de exportações comerciais adotou e aperfeiçoou legislações que combatem a prática de corrupção cometidas por empresas com negócios fechados em outros países, alinhando-as aos inúmeros tratados multilaterais que estabeleciam padrões globais contra atos de corrupção.

Todavia, este movimento não foi uniformemente crescente. Somente no início da década de 90, as grandes instituições financeiras de alcance mundial (o Banco Mundial, o Fundo Monetário Internacional, por exemplo) passaram a investir esforços mais objetivos em seus padrões internos de governança, de forma que os seus respectivos investimentos em outras instituições, ou mesmo, o financiamento de projetos tivessem critérios de seleção bem mais rígidos em relação a países ou instituições ligados à alguma prática de corrupção, tráfico de drogas ou outras atividades ilícitas (ACKERMAN, 2016, p.5).

Desde então, um movimento crescente de disseminação de iniciativas contra a corrupção praticadas por empresas junto ao setor público tem sido observado. A Organização para a Cooperação e Desenvolvimento Econômico (OCDE), a Organização dos Estados Americanos (OEA) e o Conselho da Europa (CE) são os exemplos mais claros.

A Convenção Interamericana Contra Corrupção entrou em vigor em 1997. Em seu texto traz o combate ao conflito de interesse ${ }^{2}$; a necessidade de regras de responsabilidades e normas éticas a serem seguidas pelos funcionários do setor público; medidas que impeçam o suborno de funcionários nacionais ou estrangeiros.

Em 2003, a ONU promulgou sua Convenção Contra a Corrupção. O documento é bem mais amplo que o da OCDE, por exemplo, e tem força vinculante segundo as regras do Direito Internacional. Todavia, a Convenção possui poucos mecanismos de aplicação de sanções. Por tal razão, foca seus esforços na troca de informações entre os países signatários como instrumento de fomento ao combate à corrupção (ACKERMAN, 2016, p.466). Além do

\footnotetext{
${ }^{2}$ Segundo o glossário da corrupção publicado pela Transparency International, o conflito de interesse corresponde à "situação em que um indivíduo ou a entidade para a qual trabalham, seja um governo, empresa, mídia ou organização da sociedade civil, é confrontada com a escolha entre os deveres e demandas de sua posição e seus próprios interesses privados" [Tradução livre]. Disponivel em:< https://www.transparency.org/glossary/term/conflict_of_interests>.
} 
combate ao suborno do funcionário público estrangeiro, o documento alcança o tráfico de influência ${ }^{3}$; lavagem de dinheiro ${ }^{4}$; corrupção no setor privado (ONU, 2003).

As experiências mais bem-sucedidas, entretanto, têm sido capitaneadas pela OCDE cuja Convenção anti-suborno que entrou em vigor a partir de 1999, passou a ampliar os princípios iniciais defendidos e presentes na legislação americana - FCPA (ACKERMAN, 2016, p.462).

A Convenção da OCDE é voltada ao combate ao suborno de funcionários públicos estrangeiros, demandando de seus signatários a criminalização das condutas de autoria e participação; também prevê a necessidade de sanções de natureza civil e administrativa ao agente infrator, bem como a responsabilidade da pessoa jurídica, sejam elas criminais ou administrativas (GRECO FILHO, 2015, p.28).

\subsection{A CORRUPÇÃO PÚBLICA NO BRASIL}

No âmbito das revisões legislativas de combate a corrupção, o Brasil tem apresentado uma leva de leis direcionadas para uma política mais direcionada ao combate à corrupção que, ampliam “os mecanismos de detecção e punição de atos lesivos praticados contra o patrimônio público”. Nesse sentido, é possível apontar a Lei de Improbidade Administrativa (Lei n ${ }^{\circ}$. 8.429/92), a Lei Geral de Licitações e Contratos (Lei n. 8.666/93), a Lei de acesso à Informação (Lei nº 12.527/2011), a criminalização da corrupção internacional no Código Penal (art. 337-B e 337-D) e Lei Anticorrupção (Lei nº. 12.846/13) como as mais representativas no ordenamento jurídico brasileiro para o combate à condutas ilícitas de agentes públicos e provados.

\footnotetext{
${ }^{3}$ A ONU define vantagem indevida a conduta de: "(a) prometer, oferecer ou dar para um funcionário público ou qualquer outra pessoa , direta ou indiretamente, vantagem indevida para que o agente público oficial faça uso de sua influência para obter a partir de a administração ou autoridade pública do Estado qualquer espécie de vantagem; (b) solicitar ou aceitar de um funcionário público ou qualquer outra pessoa, direta ou indiretamente, vantagem indevida para si mesmo ou para outra pessoa frente a uma autoridade pública". [Tradução livre]. Art. 18. 1 da Convenção. Disponível em:<

http://www.unodc.org/pdf/crime/convention_corruption/signing/Convention-e.pdf>.

${ }^{4}$ A ONU define a lavagem de dinheiro como a prática de " transferir propriedade, sabendo que esta é o produto de crime com o propósito de ocultar ou disfarçar a origem do ilícito ou de ajudar qualquer pessoa que seja envolvido na conduta ilícita a burlar as consequências legais de sua ação; (ii) Encobrir ou disfarçar a verdadeira natureza, fonte, localização, disposição, movimento ou propriedade ou direitos sobre propriedade, sabendo que essa propriedade é o produto do crime." [Tradução livre]. Art. 23 da Convenção. Disponível em:< http://www.unodc.org/pdf/crime/convention_corruption/signing/Convention-e.pdf>.
} 
Particularmente, as Leis nº 8.443/92 (Lei Orgânica do TCU) e nº 8.666/93 (Lei de Licitações), estabeleceram forte arcabouço jurídico para o "controle administrativoburocrático" ${ }^{5}$ do setor público brasileiro que, entre outras medidas, inclui: obrigatoriedade das licitações, suspensão de atividades administrativas do governo federal pelo Tribunal de Contas da União (TCU), termos de ajustamento de conduta, demissões de funcionários públicos, entre outras medidas (AVRITZER e FILGUEIRAS, 2011, p.23).

As iniciativas institucionais têm sido representativas no esforço do Governo brasileiro para combater a corrupção de empresas, seja no setor público, e seja no setor privado. A CGU, o MPF, o Cade e o TCU estão entre os mais representativos.

Com a promulgação da Lei $\mathrm{n}^{0} 12.527 / 11$ (acesso à informação) e da Lei $\mathrm{n}^{0}$. 12.846/13, a Controladoria Geralda União se consolidou como principal órgão direcionador das ações de fomento às práticas de introdução do Compliance junto a empresas privadas e no setor público. A estratégia adotada pelo órgão é a ação preventiva junto ao serviço público e privado para que seus agentes sempre atuem, de fato, em prol do interesse público (CGU, 2015).

\section{SISTEMAS DE COMPLIANCE}

Os programas de Compliance estão inseridos em um contexto de reestruturações estratégicas, organizacionais e tecnológicas, na construção de uma imagem empresarial forte perante clientes e fornecedores, visando a proteção do valor e da reputação corporativas (ABBI, 2004). As organizações internacionais de combate à Corrupção, promovem a adoção desses

\footnotetext{
${ }^{5}$ Avritzer e Filgueiras propõem em seu estudo que nas ordens democráticas, o controle da corrupção deve ser exercido na integração de três tipos de controle: o primeiro seria o "controle administrativo-burocrático", pautado na existência de agências especializadas, capazes de averiguar, vigiar e corrigir a eventual ação ilegítima praticada pelos agentes públicos, no exercício de suas funções, conforme a legalidade que define o conteúdo da ação legítima. As agências especializadas atuam por meio de processos de auditorias, controles de contas, correição, averiguação de cumprimento dos deveres funcionais e resultados de políticas e decisões de governo. $\mathrm{O}$ controle burocrático da corrupção é exercido a partir de uma lógica de vigilância, ou seja, para se controlar a burocracia, cria-se mais burocracia. O grande desafio da Administração Pública é fazer o controle administrativo-burocrático equilibrar o respeito ao interesse público com a eficiência da gestão pública; o segundo controle é o judicial, Judiciário deve exercer controle sobre a Administração Pública, tendo em vista um sistema de leis e regulamentos interpretados à luz de uma jurisprudência constituída pela magistratura; por fim, o terceiro controle serio o controle público não estatal, baseado no exercício apropriado da publicidade, em que o cidadão comum seja capaz de controlar a ação dos agentes públicos com base nos princípios e nos valores morais da democracia. É uma forma de controle sustentada no interesse público e que está assentada nos processos deliberativos e discursivos realizados na esfera pública. Pressupõe-se, assim, no âmbito do controle público não estatal da corrupção, um processo de ampliação da participação da sociedade civil no controle sobre a Administração Pública, tendo em vista a publicidade como princípio constitutivo da moralidade administrativa (AVRITZER e FILGUEIRAS, 2011, pág. 17-21).
} 
programas como instrumento de esforço concentrado contra práticas ilícitas no âmbito de empresas e governos.

Milford (2016) menciona a relevância dos progressos de governança no setor financeiro em todo o mundo como fator contribuinte da evolução dos sistemas de Compliance. Segundo o autor, foi em resposta ao desenvolvimento da regulamentação no setor de serviços financeiros que muitas empresas desenvolveram funções de Compliance de forma a lidar de forma mais efetiva com regras regulatórias provenientes de órgãos governamentais, minimizando os riscos de execuções penais e civis decorrentes de práticas de corrupção.

Quanto maior o volume de recursos envolvidos em projetos e negócios, tanto maior a probabilidades de práticas de corrupção. A atual preocupação com combate-la está também associada ao crescente fluxo de investimento de capital, que é fomentado ano a ano por acordos comerciais bilaterais ou multilaterais. Para se ter uma noção dos montantes envolvidos, o World Investment Report de $2017^{6}$ patrocinado pela UNCTAD (ONU), estima que o fluxo de investimento direto de capital nas economias de todo o mundo deverá aumentar cerca de 5\% em 2017 atingindo o patamar de quase US\$ 1.8 trilhões. Diante deste cenário, o aumento do fluxo de capital trocado entre os países precisou ser melhor controlado e protegido. Assim, o incremento de acordos, tratados, convenções e legislações foram um reflexo claro de preocupação dos governos de diversos países com o combate à corrupção, seja ela no âmbito empresarial ou na esfera pública.

Este movimento foi moldado ao longo dos anos com a paulatina materialização de legislações mais severas como o Foreign Corrupt Practice Act (FCPA) nos EUA; a atuação mais expressiva de entidades não governamentais como a Transparência Internacional (fundada em 1993); a Convenção Interamericana contra a Corrupção em 1996; a própria Convenção da OCDE sobre Corrupção de Funcionários Públicos Estrangeiros em 1997, a Convenção das Nações Unidas contra a Corrupção de 2005 e, enfim, o UK Bribery Act de 2010 na Inglaterra (MENDES, 2017, p. 11) .

Esta evolução legislativa e normativa que o mundo vem experimentando, fomentado pelo surgimento de ONG's de abrangência global, as constantes assinaturas de

\footnotetext{
${ }^{6}$ O relatório está disponível em:< unctad.org/en/PublicationsLibrary/wir2017_overview_en.pdf>. Acesso em: 30 set 2017.
} 
Tratados e acordos internacionais e a multiplicação de legislações especificas de combate a corrupção e de estabelecimento de programas de Compliance é uma tendência forte na realidade dos negócios transnacionais e já está sendo bem absorvida pelas empresas e pelo legislador brasileiro (PARGENDLER, 2014).

Mendes (2017) considera que um sistema de Compliance é imprescindível, especialmente para as grandes empresas, devido a fatores bem específicos. O primeiro deles é (i) a possibilidade de evitar a imposição sanções através da aculturação de seus funcionários e colaboradores e da organização das atividades da empresa, de modo a promover o cumprimento das exigências da legislação e diminuindo a possibilidade de violações. O segundo é (ii) a redução de eventuais penalidades, já que a existência de mecanismos e procedimentos de integridade estão contidos rol de atenuantes de responsabilização administrativa de pessoas jurídicas, conforme expresso no art. $7^{\circ}$, VII da Lei ${ }^{\circ}$. 12.846/13.

O terceiro benefício é (iii) a facilidade de realizar acordos com autoridades regulatórias. Dentre estes acordos, cita-se os acordos de leniência, a delação premiada e os Termos de Compromisso de Cessação (TCC). Estes institutos seriam mais facilmente acessíveis as empresas que, por terem programas de Compliance implantados, estariam mais aptas a identificar desvios de conduta em determinadas etapas da cadeia de decisões, facilitando a identificação dos agentes responsáveis. O quarto benefício seria (iv) o impacto positivo na imagem da empresa perante a sociedade. Tal impacto advém da boa reputação frente à opinião pública e aos meios de comunicação pelo simples fato de existir um sistema formal de combate à corrupção na empresa. De forma indireta, estes ganhos poderiam ser de natureza econômica, uma vez que a boa reputação da empresa poderia refletir em suas ações no mercado financeiro (se assim fosse o caso).

\section{LEGISLAÇÃO ANTICORRUPÇÃO E COMPLIANCE EM PERSPECTIVA COMPARADA}

Nesta parte estão concentradas as informações relativas às legislações anticorrupção dos Estados Unidos (FCPA), do Reino Unido (Bribery Act) e a Lei brasileira n. 12.846/13. As legislações citadas são referenciais legislativos para muitos outros legisladores, inclusive os brasileiros. A capacidade de aplicação das regras do FCPA pelo Governo americano, tornaram a lei altamente eficiente em seus propósitos, com alcance jurisdicional 
significativo, inclusive no território brasileiro. Em 2007, o US Sentencing Guidelines passou a adotar nos procedimentos judiciais relativos às empresas, a possibilidade de atenuação de penas mediante a adoção de programas efetivos de Compliance.

O Bribery Act, por sua vez, foi vanguardista em sugerir os programas de Compliance de forma explícita dentro de seu texto normativo e é mais severo, em alguns casos, que a legislação americana. Sofreu bastante influência das diretrizes presentes na Convenção da OCDE sobre o suborno de agentes públicos de 1997.

A Lei $n^{\circ}$. 12.846/13 também nasce da adesão do Brasil à Convenção da OCDE contra práticas de suborno. Incentiva os programas de Compliance como ferramentas de atenuação de pena administrativa. Também prescreve a responsabilização objetiva de empresas e traz consigo a possibilidade dos acordos de leniência e das penalidades de caráter "moral", uma vez que as empresas responsabilizadas têm suas condenações e restrições em uma lista pública.

A partir da análise de cada legislação, é possível estabelecer os pontos de convergência e os pontos em que se diferenciam. A partir da análise comparativa também é possível identificar os aspectos inovadores e as restrições de cada uma das leis. Primeiramente são apresentadas as características de cada legislação individualmente. Logo em seguida, são realizadas as análises comparativas.

\subsection{EsTADOS UNIDOS}

A lei americana mais contundente contra práticas de suborno praticadas por e contra agentes públicos é o Foreign Corrupt Practice Act (FCPA) de 1977. Esta lei proíbe a realização de pagamentos feitos por americanos a funcionários estrangeiros com o propósito de obter ou manter um negócio. Até antes de sua promulgação, as empresas americanas faziam seus negócios utilizando-se de práticas de suborno para fechar negócios com empresas e governos estrangeiros. Segundo o entendimento do Congresso Americano à época, tais práticas entravam em choque com os valores comungados na sociedade americana, além de prejudicar as próprias 
empresas, uma vez que a prática do suborno privilegiava a ineficiência e negligenciava os padrões de qualidade mínimos necessários à concorrência justa (DoJ, 1976) ${ }^{7}$.

O FCPA pune aqueles que a violam com uma infração penal com uma multa máxima de US\$ 3 milhões. Violações praticadas por indivíduos alcançam um máximo multas de US\$ 250.000 (duzentos e cinquenta mil dólares), podendo chegar até o dobro do ganho bruto ou perda decorrente da infração cometida, podendo ou não ser cumulada com prisão de até 5 (cinco) anos ao agente infrator.

A lei americana é aplicável a todas as empresas que emitem valores mobiliários registrados na Securities and Exchange Comission (o equivalente à Comissão Mobiliaria de Valores) ou que são obrigadas ao arquivamento periódico de relatórios nos termos do Securities Exchange Act de 1934. Também é aplicável a todas as pessoas físicas norte-americanas ou a qualquer empresa, associação, organização ou sociedade organizada conforme as leis americanas. Pessoas jurídicas estrangeiras que efetuarem diretamente, ou por meio de intermediários, um pagamento indevido em território americano.

Desde o início de sua promulgação, a média de casos investigados e executados baseados no FCPA mantiveram uma média tímida, mas constante, até o início dos anos 2000. Até 2007, a maior multa por crimes contra o FCPA era inferior a US\$ 50 milhões.

A partir de então, os casos se multiplicaram, bem como o valor das multas aplicadas. Agora, os maiores infratores pagam 10 a 15 vezes mais. Já o número de casos anuais também sofreu um aumento significativo. Em 2016, 27 empresas pagaram cerca de US\$ 2,48 bilhões para resolver os casos envolvendo a legislação do FCPA. Foi o maior ano de execução da história da FCPA, tanto o número de ações de execução quanto os montantes globais pagos para resolvê-los.

Atualmente, os dez maiores executados pelo FCPA americano formam um rol em grandes corporações de várias partes do mundo. A força da aplicação da lei americana se confirma pelo montante aplicado até setembro 2017 (aproximadamente US\$1,3Bi). Se forem somados os valores absolutos das multas aplicadas nos últimos 10 anos, o montante alcançado

\footnotetext{
${ }^{7}$ A história legislativa do FCPA pode ser obtido em: https://www.justice.gov/sites/default/files/criminalfraud/legacy/2010/04/11/senaterpt-95-114.pdf
} 
seria de quase US\$ 17 bilhões de dólares americanos distribuídos entre mais de 146 empresas ao longo do período ${ }^{8}$.

Partidos políticos e candidatos a cargos públicos também são alcançados por esta norma. As penas para pessoas jurídicas alcançam valores de até US\$ 2 milhões. Pessoas físicas estão sujeitas a multa de até US\$100.000,00 e prisão de até 5 anos. Os balanços e informações fiscais de empresas e pessoas físicas também estão no alcance do FCPA, cabendo penas às pessoas jurídicas de até US\$ 25 Milhões, enquanto as pessoas físicas estão sujeitas a penas de até US\$ 5 milhões e prisão de até 20 anos por fraudes fiscais.

\subsection{REINO UNIDO}

A nova legislação anticorrupção do Reino Unido abrange todas as empresas, independentemente de seu tamanho. As suas politicas de governo tem direcionado esforços para de contribuir de forma significativa para combater o suborno, criando "condições equitativas para os negócios internacionais” e promovendo “o estado de direito”, “práticas comerciais éticas”, e incentivando o “combate à suborno” como parte integrante da "boa governança corporativa” (IFF Research, 2015, p.3). Estão sujeitas à jurisdição britânica as condutas praticadas no Reino Unido e no exterior, sejam elas praticadas sob forma de corrupção ativa ou passiva. A lei também alcança a prática de corrupção ativa de funcionário público estrangeiro de Estado ou de organização internacional.

A lei estabeleceu uma inovação que endossa a relevância dos sistemas de integridade (Compliance) ao prevê possibilidade de não punição quando a empresa demonstrar que possui procedimentos adequados para prevenir o suborno (REINO UNIDO, Bribery Act Quick Start Guide, 2010, p.3).

A partir desta nova regra, essas empresas passaram a ser responsabilizadas criminalmente por delitos cometidos por pessoas associadas a eles para obter ou reter negócios ou uma vantagem na condução de negócios, a menos que a organização possa mostrar que

\footnotetext{
${ }^{8}$ Dados sobre acordos financeiros firmados por empresas com o DoJ e a SEC. Fonte: Autor. Dados The FCPA Blog. Disponível em:< http://www.FCPAblog.com/blog/2017/9/22/telia-topsour-new-top-ten-list-after-we-do-some-math.html>. Dados até setembro de 2017.
} 
possui procedimentos adequados de prevenção contra práticas de corrupção. Estes, por sua vez, devem ser proporcionais aos riscos enfrentados e às principais características do negócio, levando em consideração o seu tamanho, sua estrutura corporativa, modelo de negócios e estrutura de gerenciamento. O conceito da proporcionalidade foi desenvolvido como forma de não impactar a competitividade das empresas do Reino Unido, particularmente as pequenas e medias empresas.

Em termos gerais, o Bribery Act pune a pessoa física que prática conduta ativa ou atua de forma passiva em práticas de suborno, ou que venha a subornar funcionário público estrangeiro. Em caso de condenação sumária ${ }^{9}$, a pena incorrida é a prisão (em regime fechado) por até 12meses, acrescido de multa no limite do capital social da empresa (Section 11, (1),(a)).

Na hipótese do agente infrator for condenado após acusação formal ${ }^{10}$ (conviction on indictment), a pena é prisão por até 10 (dez) anos ou pena de multa ilimitada, ou a combinação de ambas as penas (Section 11, (1),(b)). As pessoas jurídicas estão sujeitas a pena de multa até o limite do capital social em casos de condenação sumária e a penas de multa ilimitada quando condenadas após acusação formal. As pessoas físicas e jurídicas estão sujeitas a pena de multa ilimitada nos casos de condenação por falha dos mecanismos internos de prevenção (GRECO FILHO, 2015, p.48).

Comparado o FCPA americano, o Bribery Act, mediante intervenção do Serious Fraud Office (SFO), possui números relativamente pequenos de casos analisados. Porém, sua taxa de casos sentenciados está próxima dos 87\%. Até setembro de 2017, 13 acusados foram condenados em sete casos verificados. $\mathrm{O}$ alcance do impacto financeiro líquido positivo de $£$ 325m (325 milhões de Libras Esterlinas) entre 2013 e 2017 (SFO Report, 2017).

Embora tenha surgido com toda força política e apoio social, o que lhe concedeu o status de ser considerada uma das mais restritas leis internacionais em matéria de suborno, o Bribery Act tem, na atualidade, enfrentado muitos desafios para ser realmente efetivo como o

\footnotetext{
${ }^{9}$ A condenação sumária no sistema judiciário do Reino Unido, corresponde à condenação de uma pessoa, (geralmente por menor delito), como resultado de seu julgamento perante um magistrado ou tribunal, sem a intervenção de um júri. Nestes processos, o acusado pode ser absolvido ou condenado pelo juiz singular. A conviç̧ão deste magistrado impressa em seu veredito é chamada de "convicção sumária". Este conceito jurídico foi extraído do sitio "The Law Dictionary”, disponível em:<< http://thelawdictionary.org/summaryconviction/>>. Acesso em 24 set 2017.

$10 \mathrm{O}$ “conviction on indictment” corresponde a uma condenação em tribunal de Juri de primeira instância. Extraído do sitio “The Law Dictionary”, disponível em http://thelawdictionary.org/indictment/>>. Acesso em 24 set 2017.
} 
FCPA americano. Em termos comparativos, o número de casos executados sob esta legislação é muito inferior; os casos são concluídos em prazos considerados longos e o principal órgão responsável pelas investigações e acordos (Serious Fraud Office - SFO) tem sofrido com descrenças sobre a reputação de seus membros, especialmente de seu último Diretor ${ }^{11}$.

\subsection{BRASIL}

O setor público no Brasil está começando a formar um conjunto de conhecimento e também passando a aplicar programas de Compliance em vários setores da administração pública. Para todos que queiram ou necessitem ter algum vínculo relacional com o Poder Público brasileiro, principalmente em sua esfera federal, já está vigente um conjunto de normas de caráter requisitório que precisam ser observadas.

Tais normas são capitaneadas pela Controladoria Geral da União e instituem o regime de conformidade, mediante adesão ao Pacto CGU. Nele estão previstas as regras do Código de Ética, a organização do Comitê de Ética (visando a autonomia e a blindagem de seus membros) e do Comitê de Auditoria Interna (órgão gestor do regime de Compliance, autônomo e independente).

Os mais recentes instrumentos jurídicos brasileiros a fomentar as práticas de Compliance são a Lei no ${ }^{\circ}$ 12.846/13 (Lei Empresa Limpa) e a Lei n ${ }^{\circ}$. 13.303/2016 (também conhecida por Estatuto Jurídico da Estatais, Lei de Responsabilidade das Estatais, ou simplesmente Lei das Estatais). A primeira corresponde ao compromisso brasileiro junto à OCDE. A segunda põe em perspectiva o novo regime jurídico das estatais, tornando obrigatórias as regras de Compliance.

A Lei Anticorrupção ajudou a disseminar medidas de Compliance para além das grandes empresas nacionais (que já tinham algumas práticas de controle em andamento em razão de seus respectivos negócios na esfera internacional). Com o surgimento desta legislação, grandes, médias e pequenas empresas que interagem com a administração pública direta ou indireta o governo tem um mecanismo jurídico que as direcionam a tomar ações concretas na prevenção, detecção e correção de danos ao patrimônio público (MENDES (2017, p.116).

\footnotetext{
${ }^{11}$ Ver <https://www.theguardian.com/law/2013/mar/15/fraud-office-chief-apology>
} 
A Lei 12.846/13 trouxe consigo penalidades de vão desde a aplicação de multas até a própria extinção da pessoa jurídica. Todas se concentram no âmbito administrativo. Todavia, a Lei $n^{0}$ 12.846/2013 também contempla um âmbito de responsabilização judicial (art. 19). Nestes casos, as punições são de competência exclusiva do Poder Judiciário.

As penalidades oriundas de responsabilização judicial são restrições ou impedimentos ao exercício de determinados direitos, a saber: (i) perdimento dos bens, direitos ou valores que representem vantagem ou proveito direta ou indiretamente obtidos da infração, ressalvado o direito do lesado ou de terceiro de boa-fé; (ii) suspensão ou interdição parcial de suas atividades; (iii) dissolução compulsória da pessoa jurídica; e (iv) proibição de receber incentivos, subsídios, subvenções, doações ou empréstimos de órgãos ou entidades públicas e de instituições financeiras públicas ou controladas pelo poder público, pelo prazo mínimo de 1 (um) e máximo de 5 (cinco) anos (CGU, 2016, p.61).

De modo geral, as penalidades instruídas pela lei anticorrupção abrangem atos lesivos: (i) relativos a oferecimento de vantagens indevidas; (ii) destinados a fraudar licitações e contratos administrativos e (iii) que dificultam ou impedem a atividade de fiscalização do Estado (MENDES, 2017, p.92)

Quanto às fraudes em licitações e em contratos administrativos, o art. $5^{\circ}$, IV, alíneas de "a” até g” identificam as condutas que se amoldam ao contexto das licitações e contratos. Percebe-se neste rol de condutas uma proximidade muito grande com aquelas já passíveis de punição pela Lei 8.666/93.

No âmbito administrativo, a Lei prevê em seu art. $6^{\circ}$, I, II, sanções como aplicação de multas e publicação da decisão condenatório com o propósito de dar visibilidade à sociedade daqueles que praticam condutas lesivas à Administração Pública. A publicidade dos atos lesivos também é prevista na referida Lei em seu art. 23, onde está previsto a divulgação das sanções no Cadastro de Empresas Punidas (CNEP) e no Cadastro Nacional de Empresas Inidôneas e Suspensas (CEIS), este último segundo a Lei 8.666/93 (CARVALHOSA, 2015, p.30).

As multas têm caráter punitivo e são fixadas entre 0,1\% e 20\% do faturamento bruto do último exercício anterior ao da instauração do processo administrativo, não sendo nunca inferiores às vantagens obtidas em decorrência da prática do(s) ato(s) ilícito(s). Caso não se possível a aplicação do critério do valor do faturamento da pessoa jurídica, o órgão sancionador poderá aplicar a escala que vai de $\mathrm{R} \$ 6.000,00$ (seis mil) até $\mathrm{R} \$ 60.000 .000$, (sessenta milhões), 
sendo o valor final alcançado mediante critérios de dosimetria da pena, conforme o art. $7^{\circ}$ da Lei $n^{\circ}$. 12.846/13.

As penas pecuniárias são elevadas para permitir que os ganhos advindos das práticas ilícitas deixem de ser vantajosos e, assim, tornem-se, de fato, uma barreira adicional que desestimule novas práticas lesivas. As multas são destinadas, preferencialmente, aos órgãos ou entidades públicas lesadas e, uma vez fixadas, serão executas via rito previsto nos art. 523 e seguintes do CPC/15 (QUEIROZ, 2016, p.608).

A Lei aplica-se às sociedades empresárias e às sociedades simples, personificadas ou não, independentemente da forma de organização ou modelo societário adotado, bem como a quaisquer fundações, associações de entidades ou pessoas, ou sociedades estrangeiras, que tenham sede, filial ou representação no território brasileiro, constituídas de fato ou de direito, ainda que temporariamente.

A Lei anticorrupção também é aplicável às empresas estrangeiras por fatos ocorridos em territórios estrangeiros. "O fato de uma pessoa jurídica ter uma filial ou representação no Brasil pode fazer com que seja sancionada pela Lei brasileira e por um órgão administrativo brasileiro, por atos praticados por sociedades coligadas em outros países e que não tenham qualquer relação com o Brasil” (CARVALHOSA, 2015, p.136).

Lei $n^{\circ}$. 13.303/2016, por sua vez, disciplinou a exploração da atividade econômica realizada diretamente pelo Estado brasileiro, seguindo os preceitos constitucionais previstos no art. 173 da CF/88. A lei regula atividades das empresas públicas, das sociedades de economia mista exploradoras de atividade econômica e das empresas prestadoras de serviços públicos. O novo regime jurídico das estatais uniformiza alguns procedimentos em todos os entes da federação, além de obrigar as estatais federais, estaduais e municipais.

Com relação à aplicação do Compliance, essa lei estabeleceu vários mecanismos de transparência e governança. Dentre eles, estão as regras para divulgação de informações, formas de fiscalização pelo Estado e pela sociedade, práticas de gestão de risco, códigos de conduta, constituição e funcionamento dos conselhos e requisitos para nomeação de dirigentes.

\section{CONCLUSÕES}

A prática da corrupção, especialmente o suborno de agentes públicos estrangeiros, passou a receber maior atenção de governos, empresas e organizações nas últimas três décadas. 
Avanços foram observados no âmbito da evolução legislativa dos países e na difusão das ações coletivas de monitoramento e combate à corrupção promovidas por entidades não governamentais como a ONU, a OCDE e a ONG Transparency International.

As recentes legislações apresentadas no Brasil (Leis nº 12.529/11, 12.846/13, 13.303/16) são exemplos deste novo contexto. No Reino Unido, o Bribery Act de 2010 e o FCPA de 1977 nos Estados Unidos, são os exemplos mais exponenciais no âmbito internacional. A liderança econômica e tecnológica dos americanos os levaram a se deparar com o problema do suborno antes dos demais. Obviamente que foi uma decisão política difícil, que somente começou a apresentar resultados mais expressivos no início dos anos 2000, quando o FCPA passou a ser aplicado com mais constância e atenção pelas autoridades americanas.

A adoção dos programas de Compliance visam estabelecer ambientes menos suscetíveis ao risco de investimentos estrangeiros. Para as empresas trazem a oportunidade de melhoraras seus processos internos e evitar penalizações de seus diretores ou, até mesmo, multas e penas pecuniárias que ponham em risco seus negócios. Este movimento, embora inicialmente voltado para as grandes empresas multinacionais, também está avançando as pequenas e medias empresas. Em um ambiente de negócios global e com o suporte tecnológico da internet, negócios podem ser feitos com grande agilidade em qualquer lugar e qualquer hora. O tamanho das empresas está cada vez menos relevante neste cenário.

No Brasil, a Lei ${ }^{\circ}$. 12.846/13, tem se mostrado um avanço no combate à corrupção, mas os instrumentos de Compliance ainda são menos observados como ferramentas uteis, que as ferramentas de acordos de leniência e delação premiada. As empresas veem se estruturando organizacionalmente para este novo cenário, mas a evolução ainda é pequena. É especialmente desafiador quando observada sob a ótica das pequenas e medias empresas. Este movimento ainda é percebido somente nas grandes corporações.

Grandes empresas mantem programas de Compliance ativos para alcançar maior competividade, seja pela gestação mais efetiva de risco, seja pelo cuidado em promover sua imagem frente a seus interlocutores. A preocupação com os danos à reputação da empresa frente aos seus clientes e a possibilidade da responsabilização objetiva por atos e corrupção e seus diretores e demais empregados também se mostraram preocupações representativas.

As empresas menores têm na construção das novas regras de relacionamento com o setor público um elemento mais palpável de sentido para incorporar programas de 


\section{Diogo De Almeida Viana Dos Santos}

Compliance em seu modelo organizacional. Neste contexto, pode se afirmar que os programas de Compliance ainda não se tornaram instrumentos efetivos nas empresas brasileiras, mas pequenos avanços já podem ser vistos. Por fim, o setor público vem avançando bastante progresso no fomento à implantação destes programas, com ênfase especial ao papel a CGU. Ela atua hoje como órgão referência na adoção do Compliance nas empresas privadas e públicas brasileiras.

No Brasil, pequenas e medias empresas tem um desafio maior frente ao Compliance em razão dos custos e complexidade exigidos. Restrições impostas pela legislação brasileira podem sofrem com a inercia do Poder Judiciário e com as os problemas jurídicos advindos no excesso de entes públicos legitimados para abrir processos administrativos com base na lei anticorrupção brasileira. Contudo, não há como negar que um novo paradigma se põe diante das empresas e do setor público brasileiros. Resta saber quão bem conduzido este processo será.

\section{REFERÊNCIAS}

ACKERMAN, Susan Rose. Corruption ang Government: causes, consequences, and reform. Cambridge University Press: Cambridge, 2016.

ASSOCIAÇÃO BRASILEIRA DE BANCOS INTERNACIONAIS - ABBI. Documento Consultivo “Função de Compliance”. São Paulo, 2004. Disponível em:

<www.abbi.com.br>2004>. Acesso em: 29 out. 2017.

AVRITZER, Leonardo; FILGUEIRAS, Fernando. Corrupção e Controles Democráticos no Brasil: Textos para Discussão CEPAL-IPEA, 32. Brasília, DF: CEPAL. Escritório no Brasil/IPEA, 2011. Disponível em:<

http://www.ipea.gov.br/portal/images/stories/PDFs/TDs/td_1550.pdf>. Acesso em: 28 out. 2017.

BRASIL. LEI No 12.846, DE $1^{\circ}$ DE AGOSTO DE 2013. Dispõe sobre a responsabilização 
administrativa e civil de pessoas jurídicas pela prática de atos contra a administração pública, nacional ou estrangeira, e dá outras providências. Brasília. Diário Oficial [da] República Federativa do Brasil, DF, 01 ago. 2013. Disponível em:

<http://www.planalto.gov.br/ccivil_03/_ato2011-2014/2013/lei/l12846.htm>. Acesso em 29 mar. 2017.

BREIER, Ricardo; CARRIL, Rodrigo Coutinho. Autorregulação impacta direito penal.

Consultor Jurídico. Set. 2013. Disponível em:< https://www.conjur.com.br/2013set28/autorregulacao-produz-impactos-direito-penal-empresarial>.

Acesso em: 17 mar. 2017.

CARVALHOSA, Modesto. Considerações sobre a Lei anticorrupção das pessoas jurídicas: Lei n. 12.846 de 2013. São Paulo: Editora Revista dos Tribunais, 2015.

CONTROLADORIA GERAL DA UNIÃO. Guia de Integridade Pública: orientações para a Administração Pública Federal direta, autárquica e fundacional. Brasília, 2015. Disponível em:

< http://www.cgu.gov.br/Públicacoes/etica-e-integridade/arquivos/guia-deintegridadePública.pdf $>$.

Acesso em:15 out 2017.

CUERVO-CAZURRA, Alvaro. The Effectiveness of Laws against Bribery Abroad. Journal of International Business Studies. Boston, jan. 2008. Disponível em:<

https://ssrn.com/abstract=1059001>. Acesso em: 30 out. 2017.

ESTADOS UNIDOS. Foreign Corrupt Practice Ack. Washington, abr. 1977 Disponível em:< https://www.justice.gov/sites/default/files/criminal-fraud/legacy/2012/08/29/corruptrpt-95213.pdf>. Acesso em: 30 ago. 2017.

. U.S. Department of Justice and The Enforcement Division of the U.S.

Securities and Exchange Commission. FCPA - A Resource Guide to the U.S. Foreign Corrupt 
Practices Act. 2012. Washington,, jul. 2012. Disponível em:<

www.justice.gov/criminal/fraud/FCPA and www.sec.gov/spotlight/FCPA.shtml.>. Acesso em:

25 set. 2017.

. United States Sentencing Commission, Guidelines Manual, §3E1.1 .

Washington, nov. 2016, p.533. Disponível em:< https://www.ussc.gov/guidelines/archive>.

Acesso em: 30 set. 2017.

GRECO FILHO, Vicente. O combate à corrupção e comentários à lei de responsabilidade de pessoas jurídicas (Lei n. 12.846, e 1º agosto e 2013). São Paulo: Saraiva, 2015.

IFF RESEACH. Insight into awareness and impact of the Bribery Act 2010: Among small and medium sized enterprises (SMEs). Londres, jul. 2015. Disponível em: < https://www.gov.uk/government/Públications>. Acesso em: 7 out. 2017.

KENNEDY, David; DANIELSEN, Dan. Busting Bribery. Sustaining the global momentum of the Foreign Corrupt Practices Act. Open Society Foundations. Nova York, 2011.

Disponível em:< www.law.harvard.edu/faculty/dkennedy/.../BustingBribery.pdf $>$. Acesso em: 07 set. 2017.

MENDES, Francisco Schertel; CARVALHO, Vinicius Marques de. Compliance: concorrência

e combate á corrupção. São Paulo: Trevisan editora, 2017.

MILFORD, Alun. The Nature of Compliance. Serious Fraud Office. 2016. Disponível em< https://www.sfo.gov.uk/2015/09/08/the-nature-of-Compliance/>. Acesso em 30 set 2017. MOHALLEM, Michael; RAGAZZO, Carlos Emmanuel Joppert. Diagnóstico institucional: primeiros passos para um plano nacional anticorrupção. FGV, abr. 2017. Disponível em:< http://bibliotecadigital.fgv.br/dspace/handle/10438/18167>. Acesso em 30 out. 2017. 
OCDE. Bribery and Corruption Awareness Handbook for Tax Examiners and Tax Auditors. 2009. Disponível em: < https://www.oecd.org/tax/crime/37131825.pdf>. Acesso em 18 set. 2017.

Bribery and corruption awareness handbook for tax examiners and tax auditors.

2013. Disponivel em: < http://www.oecd.org/tax/bribery-corruptionawarenesshandbook.htm>.

Acesso em 10 out. 2017

.Corporate Governance Factbook. 2017. Disponível em:<

http://www.oecd.org/daf/ca/corporate-governance-factbook.htm>. Acesso em: 23 set. 2017. Corruption. A Glossary Of International Criminal Standards. 2007. Disponível em:< http://www.oecd.org/corruption/anti-bribery/39532693.pdf > . Acesso em 20 out 2017. ONU. Convenção Contra Corrupção. 2003. Disponível em:< https://www.unodc.org/unodc/en/treaties/CAC/>. Acesso em: 30 set. 2017. Corruption and Development. United Against Corruption. 2017. Disponível em:< http://www.anticorruptionday.org/>. Acesso em: 17 set. 2017. . Manual On Anti-Corruption Policy. Global Programme Against Corruption.

Centre for International Crime Prevention. 2001. Disponível em:

<http://www.odccp.org/corruption.html>. Acesso em: 22 set. 2017.

UNCTAD. World Investiment Report 2017. Disponível em :< unctad.org/en/PúblicationsLibrary/wir2017_en.pdf>. Acesso em: 17 out 2017. PARGENDLER, Mariana. Corporate Governance in Emerging Markets. Oxford Handbook of Corporate Law and Governance. Oxford, jul. 2014. Disponível em:< http://direitogv.fgv.br/Públicacoes/working-papers>. Acesso em: 29 set. 2017. QUEIROZ, Ronaldo Pinheiro de. Responsabilização judicial daa pessoa jurídica na lei 
anticorrupção in Lei Anticorrupção e temas de Compliance. Jorge Munhós de Sousa e Ronaldo Pinheiro Queiroz (Organizadores). 2a ed. Salvador: JusPodivum, 2016.

REINO UNIDO. The Bribery Act 2010: Quick start guide. Londres, 2010. Disponível em: <http.www.justice.gov.uk/guidance/bribery.htm>. Acesso em: 17 ago. 2017. UK Foreign Bribery Strategy. Londres, 2015. Disponível em:

<http://webarchive.nationalarchives.gov.uk/20121205231543/http://www.officialdocuments.g ov.uk/document/cm77/7791/7791.pdf>.

Acesso em 30. Out. 2017.

SPAHN, Elizabeth K. Implementing Global Anti-Bribery Norms: from the foreign corrupt practices act to the oecd anti-bribery convention to the u.n. convention against corruption. 2012.

Indiana International \& Comparative Law Review. Bloomington ,2013. Disponível em: <https://journals.iupui.edu/index.php/iiclr/article/view/17871>. Acesso em: 30 set. 2017. 